\title{
Utilization of sodium bentonite to maximize the filler and pozzolanic effects of stabilized peat
}

\author{
Leong Sing Wong, Roslan Hashim, Faisal Ali
}

Introduction

Natural pozzolans have been widely used as substitutes for Portland cement in many applications because of their advantageous properties which include cost reduction and $\mathrm{CO}_{2}$ emission reduction, decreased permeability and increased chemical resistance (Papadakis and Tsimas, 2002; Rodriguez-Camacho and Uribe-Afif, 2002). A natural pozzolan is commonly identified as a highly vitreous and fine material which is predominated by silica $\left(\mathrm{SiO}_{2}\right)$ and alumina $\left(\mathrm{Al}_{2} \mathrm{O}_{3}\right)$ in composition. It is applied to mitigate alkali silica reaction (ASR) in concrete by promoting secondary pozzolanic reaction during the initial stage of cement setting. In this aspect, the ultimate function of it is to neutralize the excessive alkalinity of cement with silicic acid $\left(\mathrm{H}_{4} \mathrm{SiO}_{4}\right)$. One commercially available natural pozzolan is sodium bentonite.

Sodium bentonite is an absorbent aluminum silicate formed from the alteration of volcanic ash. Its chemical composition has a higher percentage of sodium oxide $(\mathrm{Na} 2 \mathrm{O})$ than that of calcium oxide $(\mathrm{CaO})$. It is identified as impure clay of predominantlymontmorillonite in mineralogical composition as confirmed in the $\mathrm{X}$-ray diffraction analyses of the studies of Allo andMurray (2004), Ito and Komine (2008), and Ye et al. (2010). The clay is known to possess physical properties such as small particle size, large surface area, high cation exchange capacity, high absorption capacity and high swelling capacity, which make it useful in many industries. Its compound of aluminum silicate is capable to hold a substantial net negative charge to induce large cation exchange capacity. Most of their useful characteristics are developed, or at least enhanced, when the charge on the layers is balanced by sodium ions (Churchman et al., 2002).

With such useful physical properties, sodiumbentonite is commonly used as a natural pozzolan to partially replace cement in the production of cemented materials due to its high reactivity to calcium hydroxide liberated from cement hydrolysis for the generation of pozzolanic cementation bonds. Formation of such pozzolanic cementation bonds is known to ensure continuous strength gain and improve microstructure of cemented materials. When dispersed in cement paste, it is 
capable to generate a large number of nucleation sites for the precipitation of the hydration products (Isaia et al., 2003). Such mechanismcontributes to densification and homogenization of the paste, resulting in its workability improvement, pore refinement and induction in pozzolanic activity. Furthermore, it functions as filler to improve the packing efficiency of cemented materials due to its fineness. For several decades, extensive research has been conducted on the positive effects of natural pozzolan on cementedmaterials such as concrete,mortar, brick and stabilized inorganic soils as evident in the studies of Anisur Rahman (1986), Habert et al. (2008), Isaia et al. (2003), Sabir et al. (2001), Tangpagasit et al. (2005), Velosa and Cachim (2009), and Cristelo et al. (2012)

However, research works on the application of sodium bentonite as a natural pozzolan to stabilize peat for highway construction are relatively scarce. This is mainly because of the difficulty at stabilizing the problematic soil due to its high organic content, water content and acidity. Advancement of cement chemistry in recent years has seen the possibility of using a variety of additives to stabilize peat. In addition to the function of sodium bentonite as a filler and pozzolanic additive, peat can be stabilized with calcium chloride as a cement accelerator, superplasticizer as a cement disperser, and silica sand as filler. In essence, the partial replacement of cement with sodium bentonite in stabilized peat offers an environmentally sustainable solution to reduce energy consumption of cement production, which in turn can reduce the effects of global warming and climate change. Cement industry generates around $5 \%$ of global $\mathrm{CO}_{2}$ emissions, due to carbonate decomposition (about 50\%), combustion of fuels in the kiln (about 40\%) (Velosa and Cachim, 2009). It is estimated that each tonne of cement produces approximately 1 tonne of $\mathrm{CO}_{2}$, mainly from the burning of fossil fuels and from the de-carbonation of limestone (Rehan and Nehdi, 2005). Therefore, it is a compelling idea to explore the novel usage of sodium bentonite as a natural pozzolan to optimize the strength and reduce the permeability of stabilized peat. The objective of this research work is to optimize the amount of sodium bentonite in stabilized peat so that a maximum pozzolanic activity and packing efficiency of the stabilized soil can be achieved. The optimal mix design can be applied to stabilized peat layer which functions as a shallow foundation to support highway embankment. In this way, an effective engineering response can be developed to such a geological condition of soft ground as peat. The mechanical behavior of the stabilized soil is evaluated in term of unconfined compressive strength, direct shear parameters and rate of permeability.

\section{Geological formation and classification of the peat under study}

The site of the peat under study is situated at Sri Nadi village in the 
state of Selangor in Malaysia (Fig. 1). Being part of the tropical peat swamps covering the area of Klang which is located about $35.4 \mathrm{~km}$ away from Kuala Lumpur; the site consists of peat underlain by slightly organic grayish clay with sandstone as the bedrock. Based on the application of a peat auger to explore the soil at various points of the site, it was found that the depth of the peat ranges from 1 to $3 \mathrm{~m}$. Such a depth range of peat implies that the soil can be categorized as moderately deep peat (Lim, 1989). The peat is characterized by high organic matter because it is formed from decaying plant which accumulated in water logged areas under acidic condition over thousands of years. It is a biogenic deposit which when saturated consists of about $90-95 \%$ water and about $5-10 \%$ solid material of predominantly organic matter (Warburton et al., 2004). The decomposition process of plant is rather slow due to retarded microbial degradation as a result of poor aeration in waterlogged areas. Such a slow decomposition process provides a positive environment for the formation of fibrous peat. The high water absorbing capacity of the peat influences the groundwater movement and this induces a condition for continuous accumulation of peat. Due to its high organic and water contents, the peat is extremely soft and compressible.

For the purpose of the peat physical assessment, six trial pits were excavated, each to a depth of $1 \mathrm{~m}$ below the ground surface to obtain both disturbed and undisturbed peat samples. Trial pits have the advantage of exposing the succession of strata for easy visual examination (Whitlow, 2001). Through naked-eye visualization of the trial pits, it was found that the groundwater table can be as close as $0.3 \mathrm{~m}$ from the ground surface depending on the rainfall pattern.

Classification of the peat is done based on von Post scale degree of decomposition (Landva and Pheeney, 1980). von Post scale degree of decomposition is a peat classification system based on a combination of numerous elements namely surface vegetation, chemical properties, botanical origin, physical properties and genetic processes

(Andriesse, 1988). Altogether, there are ten degrees of decomposition in von Post scale ranging from $\mathrm{H}_{1}$ (Fibrous and undecomposed) to $\mathrm{H}_{10}$ (Amorphous and decomposed). After investigation, it was found that the peat can be classified to be in the range of $\mathrm{H}_{3}$ to $\mathrm{H}_{7}$, with the deeper the peat, the higher the degree of decomposition. The color of the peat was observed to vary between brown and dark brown. The peat can be further classified based on the classification of peat in American Society for Testing and Materials (ASTM) standard.

Table 1 shows the range values of basic properties of the peat. It can be inferred from Table 1 that the peat has fiber content greater than $67 \%$, ash content less than 5\%, and $\mathrm{pH}$ value less than 4.5. By comparing such description with ASTM (2000) standard for peat classification, the soil can be classified as 'Fibric' with low ash content and described as highly acidic in term of $\mathrm{pH}$. 
Materials and methods

Description of the materials and laboratory mix designs applied for the peat stabilization

Materials utilized to stabilize the peat are Portland Composite Cement (PCC), calcium chloride, silica sand and sodium bentonite. The PCC is designed with an inclusion of $2 \%$ polycarboxylate based superplasticizer per unit weight of the cement to improve the cement workability by reducing water to cement ratio. Besides, the PCC is also enhanced with an addition of $4 \%$ calcium chloride by weight of the cement to accelerate the cement hydration process in the stabilized soil.

To increase the solid particles and enhance the packing effect of the stabilized peat, well graded silica sand was prepared as filler for the peat stabilization. The particle size distribution of the well graded silica sand is tabulated in Table 2. To assess an optimal filler effect of sodium bentonite, the clay was prepared at various compositions ranging from 5 to $40 \%$ for the peat stabilization.

Full text available at :

http://ac.els-cdn.com/S0013795212003043/1-s2.0-S0013795212003043-main.pdf? tid=a2053ce6-66e4-11e39514-00000aacb361\&acdnat $=1387261970$ 2f749daf097c804708e4906fc2c5f939

http://www.sciencedirect.com/science/article/pii/S0013795212003043 